\title{
Mechanical and Thermal Properties of Solid Waste-Based Clay Composites Utilized as Insulating Materials
}

\author{
Abdul Hai Alami* \\ Sustainable and Renewable Energy Engineering Department, University of Sharjah, Sharjah, UAE, 27272
}

\begin{abstract}
The use of masonry clay bricks with different filler materials and dispersed solid phases is investigated. Masonry bricks from two regions in the Middle East, famous for buildings made of clay composites are investigated and compared in order to better enhance the mechanical and thermal properties of the bricks used in terms of strength and insulation. Each region has specific clay type, different filler materials and also different materials suitable to be solid dispersed phases. For example, While Jordan has an abundant supply of olive husk and straw as it has pronounced foliage, the UAE has scarce water resources, and hence palm trees are of the few plant species that can endure in such an environment. It has been concluded that the clay-straw-husk has better thermal insulating properties, but less toughness (area under the stress-strain diagram) than the clay-fronds-pits variety of clay composites.
\end{abstract}

Keywords: Masonry clay composite, date pits aggregate, olive husk, green insulation materials

\section{Introduction}

Increasing energy prices and depletion of natural resources are becoming pressing realities that need novel solutions. The availability of resources for aggregate additives drawn directly from nature is decreasing, and thus viable alternatives to be considered are either recycled rubble, or aggregate waste material from agricultural processes [1-4].

As part of the early cradles of human dwelling in the Middle East, Jordan and the United Arab Emirates both have many historical sites that were built using unfired clay bricks mixed with locally available filler materials. In the UAE, palm tree fronds was used as a filler material to prevent drying-induced cracking in the clay bricks that were reinforced with local aggregate materials, varying from coral reef shells to sedimentary rocks, depending on the proximity to sea or mountain [5]. In Jordan, the filler used was the more available straw (hay) that was sometimes mixed with debris or crushed rocks [6]. These clay bricks with their fillers were able to support and sustain human activities for many decades under extreme weather conditions, be it in winter or summer. Thus, the solution of a futuristic problem would be found lying in the past. The motivation behind this work is to establish the suitability of unfired clay bricks that have been used for generations in both Jordan and UAE as a masonry material for construction of dwellings that allow natural climatization through their thermal insulating properties.

\section{Theoretical Formulation}

The analysis of composite clay bricks cannot be conducted in a manner similar to alloys made by thermally induced material diffusion, or like the processing of polymer-based composites. The formulation for failure analysis of masonry clay bricks will follow a fracture mechanics approach, where fracture toughness formulae are used.

The two composites, subject of the current study, have two different filler materials and different dispersed phase materials. In the case of the clay-straw-husk composite, the filler is dried straw and the dispersed phase is the solid waste from olive pressing process (crushed olive pits and olive skins), while in the case of the clay-fronds-pits composite, the filler is dried fronds and the dispersed phase is crushed dates pits. The chemical composition of both dispersed phases are shown in Tables 1 and 2.

Table 1

${ }^{*}$ Corresponding author. Tel.: +971561605355

Fax: +97165585191; E-mail: aalalami@ sharjah.ac.ae

(C) 2013 International Association for Sharing Knowledge and Sustainability

DOI: $10.5383 /$ ijtee.06.02.007 
Chemical composition of date pits on dry matter basis [7]

\begin{tabular}{lr}
\hline Item & $\%$ \\
\hline Chemical composition on crude fibre basis & \\
Crude protein & 6.0 \\
Ether extract & 8.0 \\
Crude fibre & 13.5 \\
Ash & 1.0 \\
NFE $^{\mathrm{a}}$ & 71.5 \\
Starch $^{\text {Non-starch }}$ & 3.0 \\
${ }^{\text {a }}$ Nitrogen-free extract $=100-$ (crude protein + ether extract + crude fibre + ash).
\end{tabular}

Table 2

Chemical ash composition of olive solid waste material [8]

\begin{tabular}{lllllllll}
\hline & $\mathrm{Na}_{2} \mathrm{O}$ & $\mathrm{K}_{2} \mathrm{O}$ & $\mathrm{CaO}$ & $\mathrm{MgO}$ & $\mathrm{SiO}_{2}$ & $\mathbf{P}_{2} \mathrm{O}_{5}$ & $\mathrm{Fe}_{2} \mathrm{O}_{3}$ & $\mathrm{MnO}$ \\
\hline Pit (\%) & 0.95 & 42.88 & 8.44 & 1.51 & 12.98 & 3.43 & 0.91 & 0.05 \\
Pulp (\%) & 0.38 & 39.61 & 7.52 & 2.04 & 18.51 & 6.22 & 1.37 & 0.04 \\
R. O. cake (\%) & 0.51 & 34.62 & 8.50 & 1.87 & 24.59 & 5.64 & 1.34 & 0.04 \\
COMWW (\%) & 0.94 & 57.29 & 2.84 & 2.49 & 1.14 & 7.84 & 0.37 & 0.03 \\
\hline
\end{tabular}

The dispersed phase size and distribution within the matrix are important parameters in when investigating the effect of adding it to a matrix.

For large-particle composite, the enhancement in the elastic modulus can be found using the rule of mixtures [9], which has an upper and a lower bounds, as follows:

$$
\begin{aligned}
& E_{C}(u)=E_{m} V_{m}+E_{p} V_{p} \\
& E_{C}(l)=\frac{E_{m} E_{p}}{V_{m} E_{p}+V_{p} E_{m}}
\end{aligned}
$$

Raw data of the mechanical properties of the two dispersed phases in question, i.e. the olive husk and the date pits, are not available in literature. Thus, and as will be explained shortly in the experimental procedure, a control group that contains no dispersed phase will be made of each matrix (clay + husk and clay + fronds) depending on the region where clay is indigenous.

The failure analysis of such a brittle composite is expected to exhibit negligible elastic deformation, and thus a linear correlation, analogous to the one suggested by [10], can be made between its strength and fracture toughness, $K_{\mathrm{IC}}$. This will also be compared to the reported strength value of 19.0$90.0 \mathrm{kPa}$ suggested by the same reference.

The clay specimen thickness is finite, and thus in fracture mechanics approach depends on calculating the corrected plain strain fracture toughness, $\mathrm{K}_{\mathrm{IC}}$. The date pits shape lends itself to classical elliptical shape of crack in literature. The governing equation for such a crack is in the form [11]:

$$
K_{\mathrm{IC}}=\sigma(a \pi)^{1 / 2} f(b)
$$

where $\sigma$ is the nominal stress away from the crack, a is half the size of the pit and $f(b)$ is a secant correction function for plain-strain specimens with the size of the pit with respect to specimens size.

This work will also focus on assessing the manufacturability of sheets made from the two composites of clay-fronds-pits and clay-straw-husk and usage as an insulating material. This will add another significance to the project as an organic, benign and biodegradable material is used for thermal insulation purposes to replace foams and Rockwool.

\section{Experimental Procedure}

To test the mechanical properties of the clay composites for the two regions, sets of specimens were prepared from mixtures that contained the clay material from respective geographic area, along with metered amounts of the filler and aggregate materials. Then, each specimen set was tested in compression to determine the mechanical properties, and also the thermal conductivity coefficient was measured using thermal conductivity apparatus.

\subsection{Specimen preparation:}

\subsubsection{Clay-straw-olive husk:}

The specimens contained two main sets, one void of olive husk, which will be the control group and the other with $40 \%$ wt. of olive husk. Clay collected from the Karameh region in Jordan was mixed with straw in the presence of plasticizing water to aid in moulding. The straw amounted for $10 \%$ of the weight of the specimen, as recommended by [12]. Three specimens of each of the two sets were made, and two more sets were made following the exact procedure, but each were placed in a furnace for 5 hours at $125^{\circ} \mathrm{C}$ after the standard drying within a drying furnace at $55^{\circ} \mathrm{C}$ for 8 hours, that all 12 specimens went through. The moulds and specimens are shown in Figure 1.

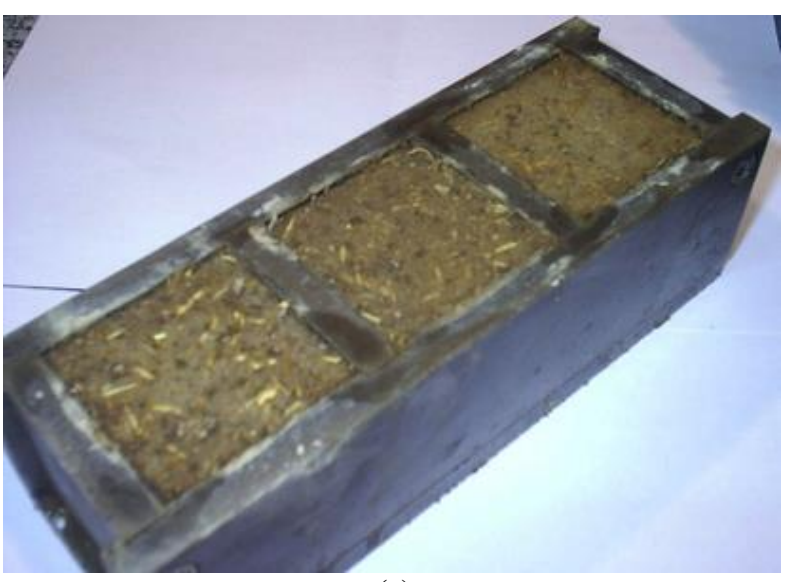

(a)

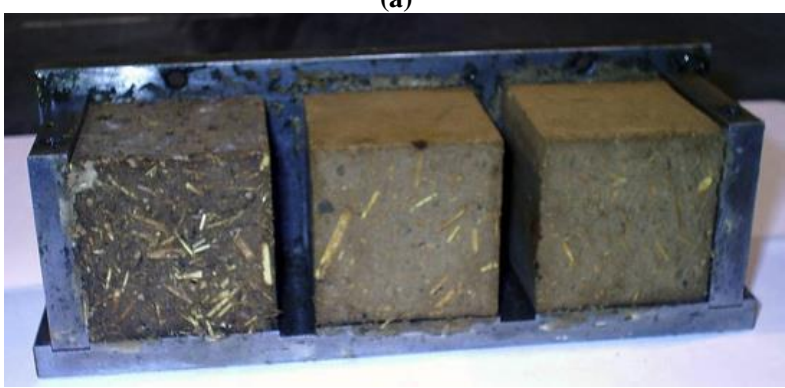

(b)

Fig. 1. Clay-Straw-Husk specimens (a) in mould and (b) demoulded. 


\subsubsection{Clay-fronds-crushed olive pits:}

In a manner identical to the one described in section 3.1.1, palm fronds were dried, and added to the clay to also form $10 \%$ of the total weight, and plasticizing water was added. The clay was collected from the region of Ras Al Khaimah in the UAE, where traditional houses made of clay still exist, and dates back to the turn of the 20the century [13]. Crushed date pits were then added and constituted $20 \%$ of the total weight. The specimens were then placed within a furnace and dried at $55^{\circ} \mathrm{C}$ for 8 hours. No fired specimens were made for the clay-fronds-pits specimens at this point. The moulds and specimens are shown in Figure 2.

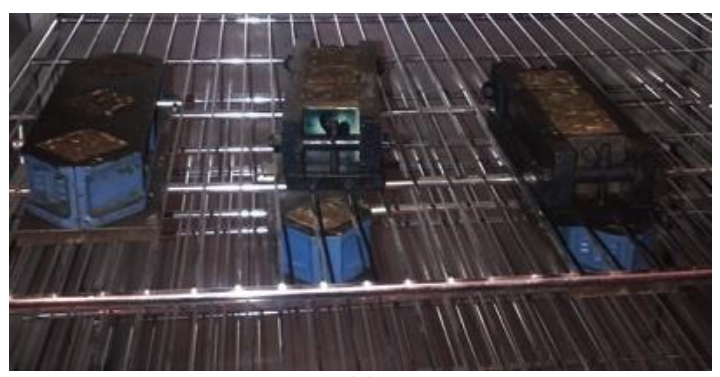

(a)

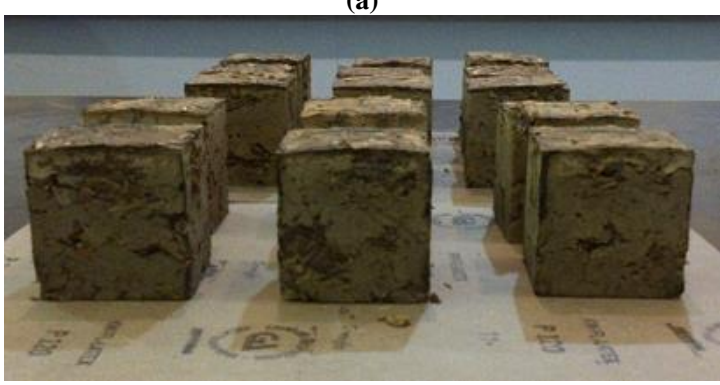

(b)

Fig. 2. (a) Specimens in drying furnace, and (b) demoulded specimens

The two types of specimens described in the previous sections have a cubical, $50 \times 50 \times 50 \mathrm{~mm}$ dimensions, and all of them were checked for dimensional consistency after moulding.

A final specimen of $40 \%$ husk and another made of clayfronds-pits of the dimensions $150 \times 150 \times 20 \mathrm{~mm}$, which will be later used to assess the thermal conductivity of both types.

\subsection{Compression tests}

Each of the produced specimens was tested in compression. 3 specimens of identical composition were tested for statistical purposes, and the average of each of the tests was plotted and used. The tests took place using a proving ring to apply the load. The proving ring has a maximum load of $2.0 \pm 0.1 \mathrm{KN}$ and measures displacement to the accuracy of $\pm 0.01 \mathrm{~mm}$. The test was conducted on a single specimen produced earlier, and it revealed that the load and displacement ranges of the ring are satisfactory to obtain the mechanical properties of the rest of the specimens. The test setup is shown in Figure 3 below.

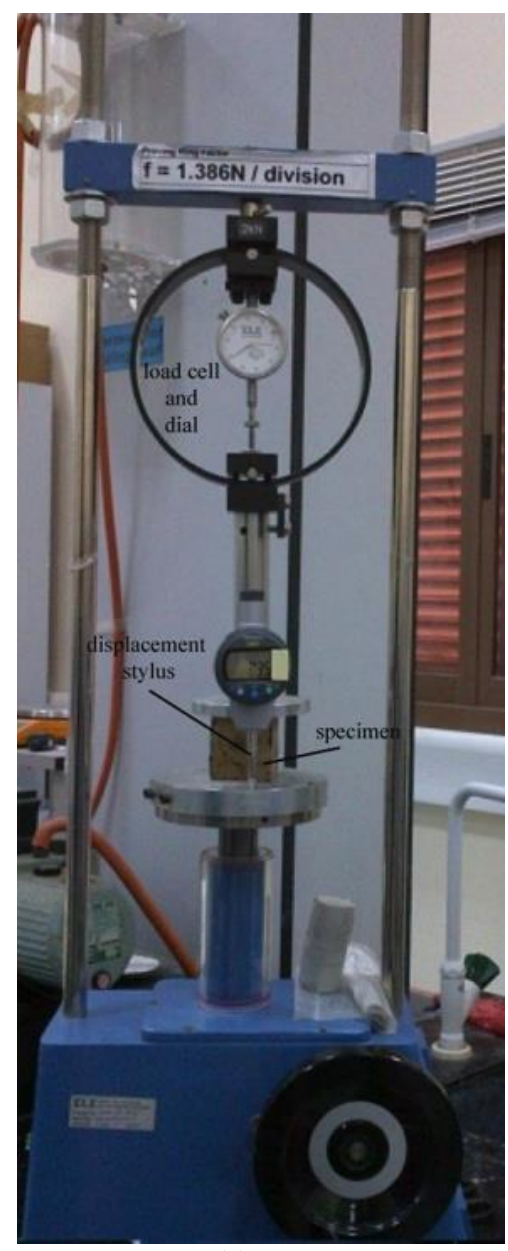

(a)

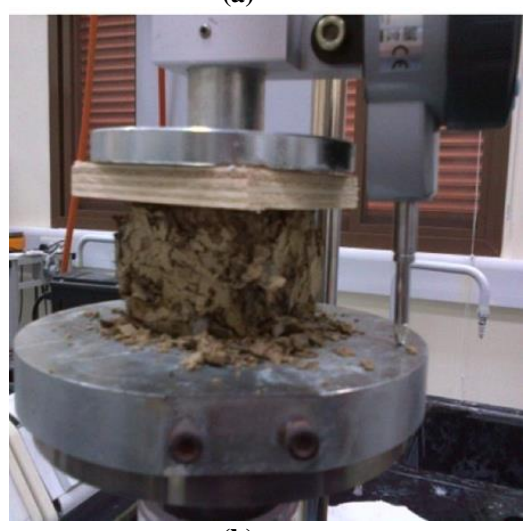

(b)

Fig. 3. Experimental Setup (a) the proving ring and (b) a failed specimen

The failure criterion for all specimens was such that if obvious disintegration of the material is obvious, the test is terminated. All specimens would continue to carry the load even after fracture, due to pronounced friction and shear along the failure plane; long after the material has reduced to two (or more) pieces. 


\subsection{Thermal conductivity test}

The thermal conductivity of the composite was measured following the ASTM E1225 standard. The specimen prepared from clay, fronds and crushed pits was placed in the thermal conductivity-measuring machine (made by P.A. Hilton) located at the Thermodynamics Lab of Higher Colleges of Technology, Al Ain, to measure their thermal conductivities. Heat flux enough to keep the input temperature at $50^{\circ} \mathrm{C}$ was applied, and silicon pads were used at the top and bottom of the specimens to ensure a perfect thermal contact between the measuring sensors of machine and the specimen being tested. Specimens were left in the machine for 4 hours; enough to achieve steady state heat transfer.

\section{Results and Discussion}

Compression and thermal conductivity tests were conducted to determine the mechanical and thermal properties, respectively. The results are presented and discussed below.

\subsection{Compression test}

Type The proofing ring was used to determine the relation between loading and displacement. The data was averaged for all sets of specimens between the three specimens of each set. The results were consistent, and showed a maximum of $2 \%$ error.

\subsubsection{Compression test for control specimens}

The control group of specimens that contained no olive husk (both fired and unfired specimens) and ones without date pits for the clay-fronds specimens is shown in Figure 4.

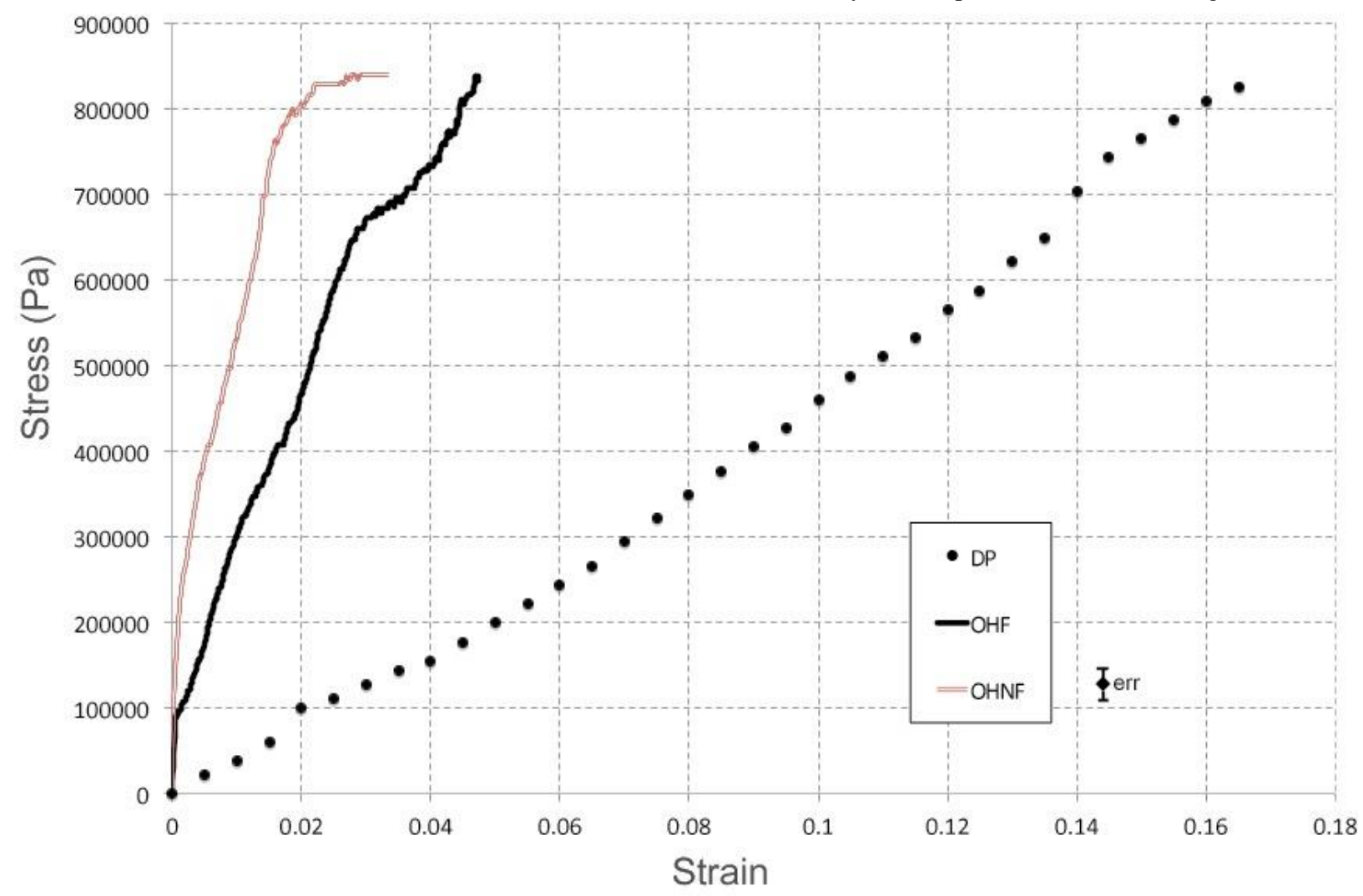

Fig. 4. Stress-strain diagram for control group specimens designated Date Pits (DP), Unfired Olive Husk (OHUF) and Fired Olive Husk (OHF).

From the figure, two main observations can be made. First, the effect of firing the clay enhances the toughness of the specimens, and also their ultimate strength. This is evident from the difference between the two clay-straw-husk curves in their fired and unfired variations, where an enhancement of around $80 \%$ is shown in toughness. Since no dispersed phases are present in the control groups, the main difference between the OHF and OHUF on one hand and the DP specimens on the other exists only in the type of clay used, and the filler material being either straw (OHF and OHUF) or palm fronds (DP).
The second, DP specimens show greater toughness, although they are less stiff than their straw-filled clay counterparts. One explanation could be that, although both straw and fronds were dried, the frond leaves are significantly stiffer than straw, which is a type of grass that is widely used in agricultural areas as a filler for masonry materials.

\subsubsection{Compression tests with dispersed phases}

The compression test results for the specimens with dispersed phases added are shown in Figure 5. 


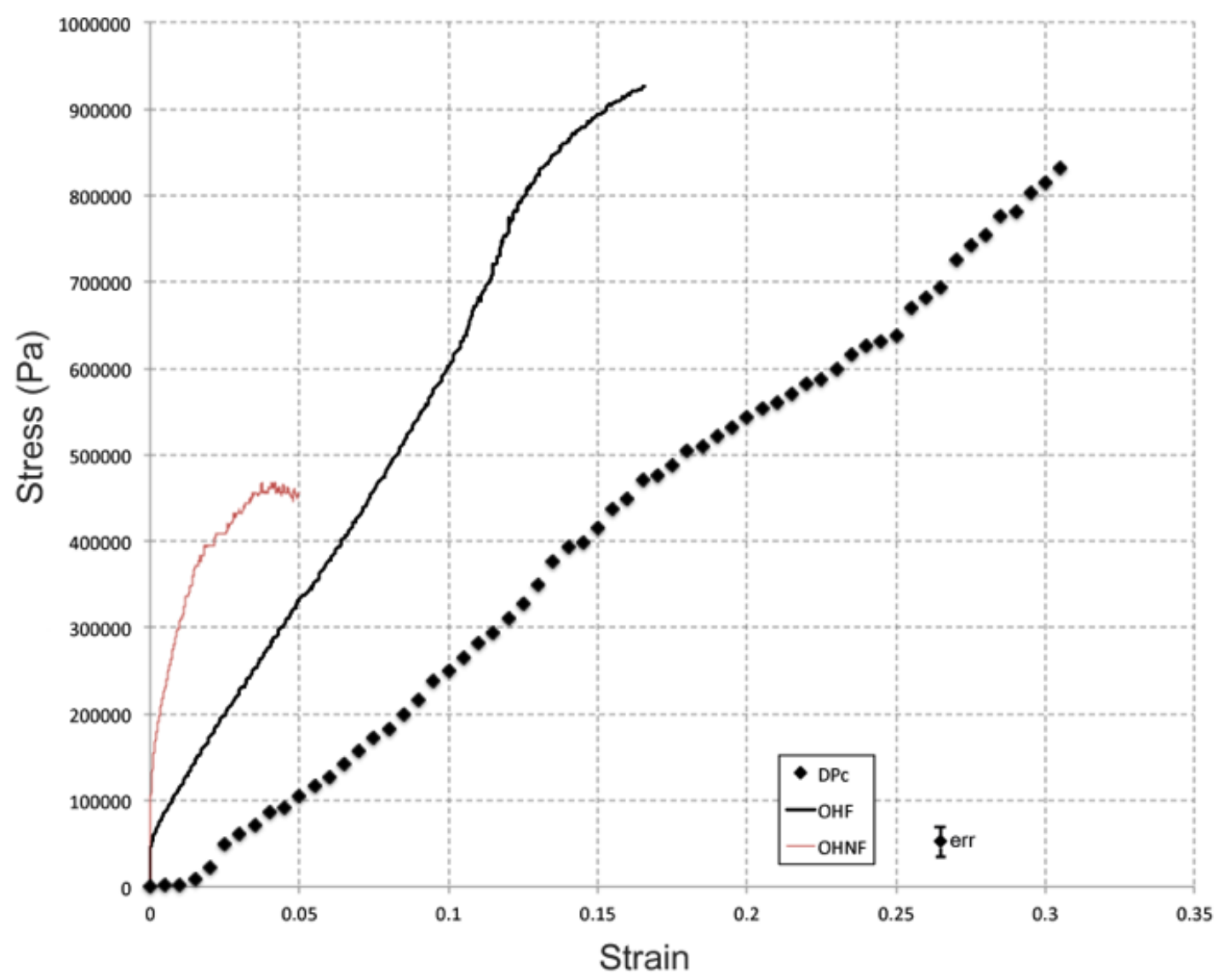

Fig. 5. Stress-strain diagram for specimens containing Date Pits (DP), Unfired Olive Husk (OHUF) and Fired Olive Husk (OHF).

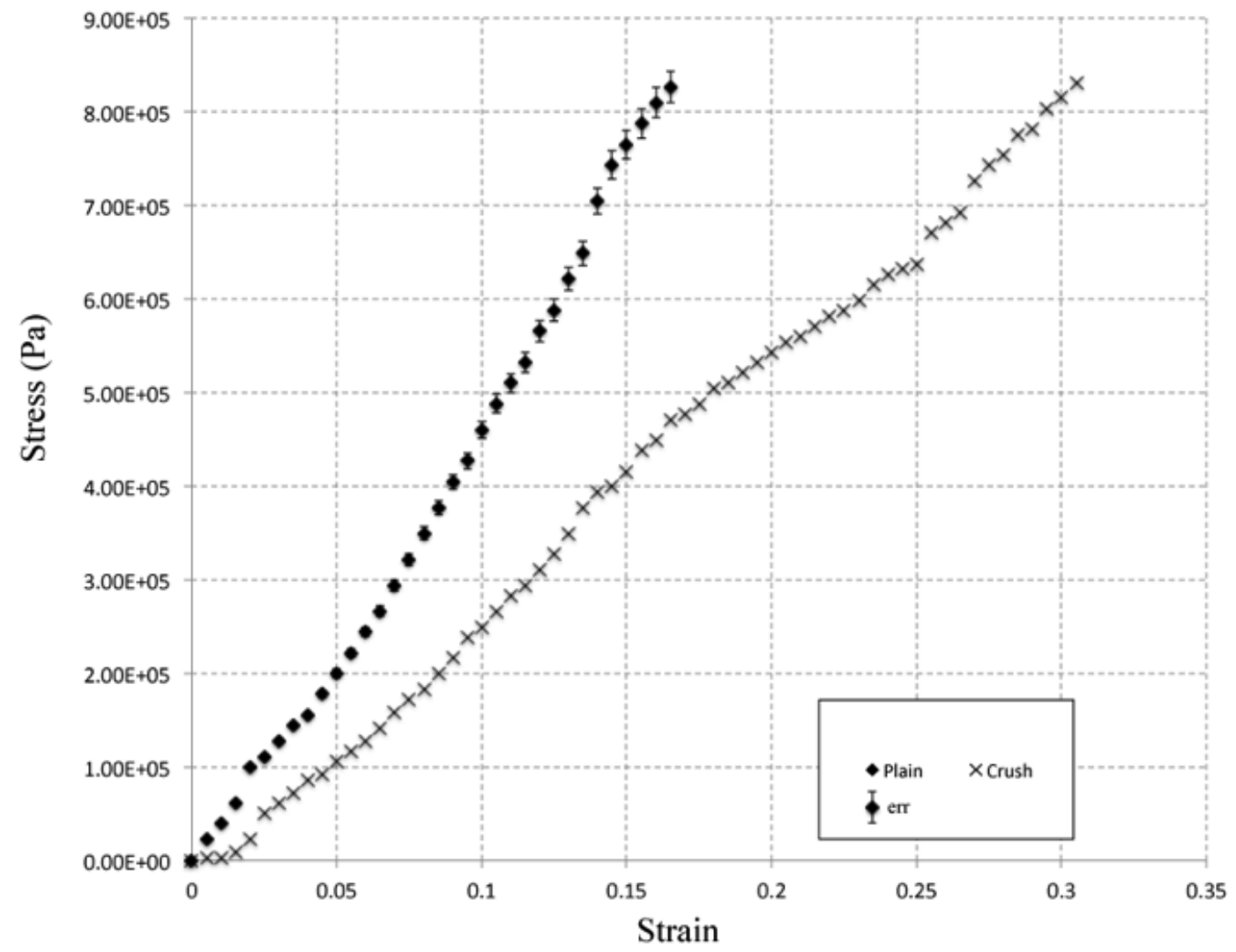

Fig. 6. Stress-strain diagram for control specimens (clay + straw) and specimens containing (clay + straw + crushed pits) 
Figure 5 indicates, in general, that there is tangible enhancement to the mechanical properties due to the addition of the dispersed phases, i.e. pits and husk, with the pits addition exhibiting a much higher toughness (around $46 \%$ more area under the stress-strain diagram). IT is also noticed that the effect of firing specimens containing olive husk at $125{ }^{\circ} \mathrm{C}$ has great benefits for the specimens containing $40 \%$ olive husk. And although these specimens had the highest values of ultimate stress, the ones containing fronds and pits with their higher toughness will have better manufacturability, and thus would be recommended for nonload bearing applications like insulation sheets.

A comparison of the effect of adding date pits to the clayfrond matrix is further explored by plotting the stress-strain diagram for both, as shown in Figure 6.

The toughness enhancement is quite clear, with even the value of the maximum stress value being around $5 \%$ higher.

\subsection{Thermal conductivity experiments}

The two specimens made of clay-straw-husk and clay-frondspits were tested using the setup described in section. The results for the test have revealed a value of $\lambda=0.09 \pm 0.02$ $\mathrm{W} /(\mathrm{m} \cdot \mathrm{K})$ for the clay-straw-husk specimen, and $\lambda=0.4 \pm 0.02$ $\mathrm{W} /(\mathrm{m} \cdot \mathrm{K})$ for the clay-fronds-pits. Although the latter value is within the range listed for sand-based composites [14] and thus we conclude that there is no pronounced enhancement that the addition of frons and pits to clay has introduced, the value reported for the clay-straw-husk specimen showed a great reduction in the thermal conductivity value. This makes the clay-straw-husk composite a better candidate for thermal insulation purposes. The specimen used to measure the thermal conductivity is shown in Figure 7.

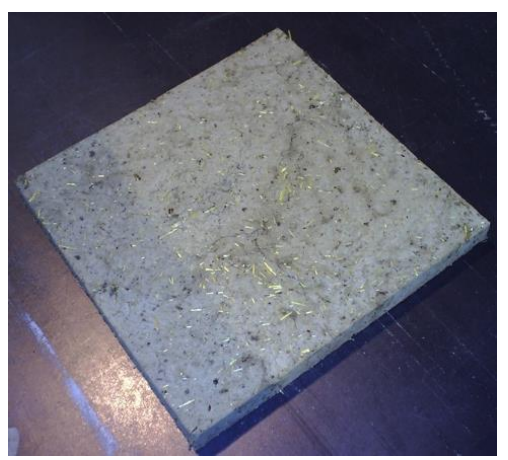

Fig. 7. Specimen made for measuring thermal conductivity

\section{Conclusion}

The utilization of solid waste material in enhancing the mechanical and thermal properties of masonry clay bricks was investigated. Specimens made from locally available clay in two regions of the Middle East, namely Jordan and UAE, both historically known for supporting early civilizations in dwellings that supported life in harsh climates using buildings made of clay. The addition of dispersed phases to strengthen the clay-filler matrix was selected as a solid waste material indigenous to each of these countries. For example, Jordan is famous for an enormous olive crop that is pressed for olive oil every year, producing a large amount of solid waste in the form of olive husk. In the case of UAE, dispersed phase consisting of date pits is a suitable candidate due to its availability and durability. The composite made of clayfronds as a matrix with date pits as a dispersed phase exhibited higher toughness than the composite made of claystraw matrix with olive husk as the dispersed phase. This makes it a better alternative when mouldability or manufacturability is an issue. Results for thermal conductivity, however, were in favor of the clay-straw-husk composite, which scored lower conductivity, at $\lambda=0.09 \pm$ $0.02 \mathrm{~W} /(\mathrm{m} \cdot \mathrm{K})$, making it a better candidate as a thermal insulator.

Future work on this matter can combine both fillers and dispersed phases with clay from both regions, with the better combination recommended as a tough material that has good thermal insulating properties.

\section{References}

[1] F. Bektas, K. Wang, H. Ceylan, Effects Of Crushed Clay Brick Aggregate On Mortar Durability, Construction and Building Materials 23 (2009) 1909-1914

[2] Gökhan Görhan, Osman Simsek, Porous Clay Bricks Manufactured With Rice Husks, Construction and Building Materials 40 (2013) 390-396

[3] Abdul Hai Alami, Experiments On Olive Husk-Addition To Masonry Clay Bricks On Their Mechanical Properties, And Their Application And Manufacturability As An Insulating Material, Advanced Materials Research 83-86, 874-880

[4] J.E. Oti, J.M. Kinuthia, Stabilized Unfired Clay Bricks for Environmental and Sustainable Use, Applied Clay Science 58 (2012) 52-59

[5] Jakub Czastka, Traditional Architecture of Abu Dhabi: The Summer House of Sheikh Shakhbut, Tribulus 7 (1997) 9-11

[6] "History of Jordan, from Antiquity to Modernity", Information Bureau of the Embassy of the Hashemite Kingdom of Jordan

[7] A. Aldhaheri, G. Alhadrami, N. Aboalnaga, I. Wasfi, M. Elridi, Chemical Composition Of Date Pits And Reproductive Hormonal Status Of Rats Fed Date Pits, Food Chemistry 86 (2004) 93-97

[8] Teresa Miranda, Alberto Esteban, Sebastián Rojas, Irene Montero and Antonio Ruiz, Combustion Analysis of Different Olive Residues, Int. J. Mol. Sci. 2008, 9, 512-52

[9] William D. Callister Jr, Materials Science and Engineering: An Introduction, sixth ed., Wiley, New York, 2010

[10] Jun-Jie Wang, Jun-Gao Zhu, C.F. Chiu, Hui Zhang, Experimental Study On Fracture Toughness And Tensile Strength Of A Clay, Engineering Geology 94 (2007) 65-75

[11] Marcel Dekker, Practical Fracture Mechanics in Design, first ed., CRC Press, 1996

[12] B. A. Jubran, S. M. Habali, M. A. S. Hamdan, Adnan I. O. Zaid, "Some Mechanical and Thermal Properties of Clay Bricks for the Jordan Valley Region", Materials and Structures/Mat riaux et Constructions, Vol 21, pp 364-369, 1988.

[13] Jakub Czastka, Traditional Architecture of Abu Dhabi: The Summer House of Sheikh Shakhbut, Tribulus 7 (1997) 9-11

[14] Frank Kreith, Raj Manglik, Mark Bohn, Principles of Heat Transfer, seventh ed., Brooks/Cole, June 2010 